\title{
In between psychology
}

\section{P.N. Johnson-Laird}

In Search of Mind: Essays in Autobiography. By Jerome Bruner.

Harper \& Row: 1984. Pp.306. \$19.25, £14.

THE imaginary line that divides the two cultures runs through the middle of psychology. On one side lies a science that aims to explain the mechanisms underlying behaviour and the mind. Its practitioners propose explicit theories, often modelled in the form of computer programs or axiomatized within a formal calculus, and attempt to test them in controlled experiments on human beings or animals. On the other side is a more diffuse and older subject, sometimes called "humanistic" psychology. It assumes that the most important aspects of mental life may not be open to scientific explanation. Its practitioners are committed to human values, to the "growth" of individual personalities, and to the healing of sick or disturbed minds.

For once, the grass looks paler on the other side of the fence. The scientists perceive their humanistic colleagues as idealistic and soft-headed social workers, whose ideas take far too much for granted, and who seem uninterested in submitting them to experimental test. The humanists see their opposite numbers as hard-nosed but shortsighted scientists wedded to the experimental investigation of trivial phenomena such as the distribution of reaction times to simple visual stimuli. In fact, the line of demarcation is not a sharp one, but a shifting boundary between two regions in imminent danger of total dislocation. What is remarkable about Jerome Bruner, the author and protagonist of this book, is that he straddles the divide.

Bruner tells the story of how a bright middle-class New York Jewish boy, who was blind for the first two years of his life, grew up to become a world-famous psychologist. His very first experiment was an unwitting childhood replication of Edmund Gosse's attempt to demonstrate the consequences of idolatry. Gosse knelt and worshipped a chair in the expectation of being on the receiving end of a thunderbolt. Bruner questioned the existence of God, and adopted a more direct procedure. In the middle of a thunderstorm, he challenged the Almighty to strike him down. Gosse reports that his religious faith survived unscathed but henceforth he put less trust in the testimony of his father. Bruner with hindsight also offers a Freudian interpretation of his experiment, though it may be significant that he later ran into trouble at college for refusing to attend compulsory chapel.

Few people of Bruner's generation

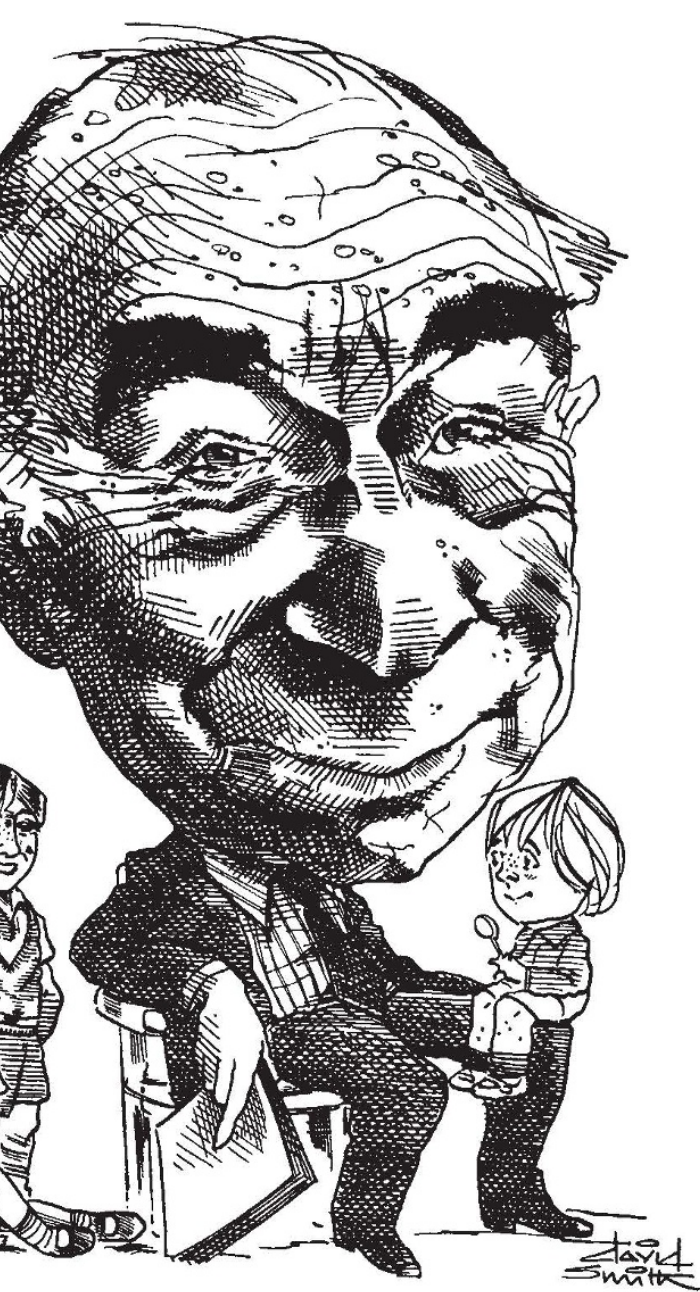

related, revolutions in American psychology: the recovery of the mind as a respectable topic for scientific investigation, and the re-discovery of the role of unconscious mental processes.

Bruner began by setting a new fashion in the study of perception, the so-called "New Look". He and his colleagues carried out a series of experiments showing that people's desires, attitudes and expectations can affect the way they see the world. For example, children overestimate the size of coins, and children from poor homes make a greater error than those from affluent ones. Other studies showed that an emotionally charged word sometimes takes very much longer to recognize than a more neutral word - as though the perceptual system defends the perceiver from the unpleasantness associated with the word. Such a result still strikes some psychologists as too paradoxical to be believed - how could a word be threatening unless it was recognized? - but it would hardly have surprised Helmholtz, who believed that perception was an unconscious process culminating in consciousness. The "New Look" gave rise to a long methodological wrangle, but it established Bruner's reputation. Never one to present a stationary target, he turned to the study of thinking, and started a new fashion for experiments on how people form concepts defined in terms of the conjunction or disjunction of properties. When he and George Miller set up the Harvard Center for Cognitive Studies at the beginning of the $1960 \mathrm{~s}$, the mind had finally been given back to American psychologists as a necessary topic for scientific investigation.

Despite his central role in these affairs, Bruner retains some sceptism about a full-blooded scientific approach. He writes:

I think I am suspicious of 'formal' models of human behaviour -

probably set out to be psychologists. He tells us that he "landed in" the discipline because of the place (Duke University), the people (Berlin-trained Gestalt psychologists) and the times (the 1930s). The initial brush with Gestalt psychology contributed to his later success, because the United States was then dominated by the intellectual isolationism of the Behaviourists. They were so hard-headed about scientific psychology that they took the mind to be a ghost in the machine, which could be exorcised by the proper study of nerve, muscle and behaviour. Bruner never succumbed to Behaviourism, and he was to take a central part in the two major, and theories couched exclusively in mathematical terms or in abstract 'flow diagrams'. I have always been sympathetic to the metaphors of computation and information processing, but resistant to getting trapped in their necessary measurement constraints. Perhaps I feel that such systems of measurement trap you on their flypaper while you are still wanting to fly. Their precision exacts a very high price in the abandonment of imagination.

Here, Bruner's insight into himself may have deserted him. It is a fallacy to assume that theories modelled in the form of computer programs demand any more precise constraints on empirical measurements than those couched in the vernacular. The real constraint of computer 
programs is that they do not allow the theorist to take too much for granted; this constraint can liberate the imagination. The truth is that Bruner has no taste for this sort of theorizing, perhaps because he lacks the necessary background. Indeed, at one point, he refers to himself as a "nonscientist".

The danger of a dislocation between Bruner's scientific and humanistic tendencies reaches a maximum in his essay on consciousness. He distinguishes its evolutionary origin as a "tool" for solving problems from its "ornamental" role as a vehicle for "making visible the unseen, making possible the unimagined". He draws a parallel distinction between two modes of discourse - the formal scientific mode, and the narrative mode of the poet and myth-maker. The essay itself jumps from one mode to the other, its very form buckling under the pressure.

After the triumphs of the "New Look" and the study of thought, which were both to launch a thousand experiments into the literature, Bruner shifted his attention to schools, and to the reform of the curriculum. His best ideas were thwarted by politicians, but he nonetheless served to shape certain aspects of the educational system in the United States. Subsequently, he returned to the laboratory to investigate children's cognitive development. As he candidly admits, his work here was too close to Piaget's, and it was less well received. At the beginning of the 1970 s after the Harvard Center had been disbanded, Bruner, always ready to move, came to England to the Watts professorship of psychology at Oxford. One of the most absorbing essays in the book describes his life in universities, and compares Harvard and Oxford to the latter's disadvantage. In retrospect, one can see that although the Oxford intellectual milieu suited him, the department of psychology did not. It lay entirely on the scientific side of the border, whereas he retained his scepticism. Ultimately, bored by "Bruner-bashing"' seminars, he returned to the United States.

Although Bruner has written a number of widely praised books, this one is his best. Its success rests on two factors. One is Bruner's talent for being at the centre of the cognitive revolution. The other is his skill in re-creating on paper his own personality and cast of mind - a vivid, and very unEnglish mixture of passion, restlessness, gregariousness and intellectuality. $\mathrm{He}$ is indeed an intellectual first, a psychologist second and a scientist third. His book is bound to be widely read by psychologists; it should be read by anyone who wants to understand what has happened to American psychology in the past half century.

P.N. Johnson-Laird is Assistant Director of the Medical Research Council's Applied Psychology Unit, Cambridge. His most recent book, Mental Models, was published by Cambridge University Press late last year.

\section{Through to another dimension}

\section{Thomas Banchoff}

The Planiverse: Computer Contact with a Two-Dimensional World.

By A. K. Dewdney.

Poseidon, New York: 1984. Pp.267.

Hbk \$16.95, pbk \$9.95. To be

published in the UK on 11 May by

Picador, hbk £7.95, pbk£2.95.

ONE hundred years ago Nature published a review of Flatland: A Romance of Many Dimensions, Edwin Abbott Abbott's classic tale of A Square, a two-dimensional creature who encounters a visitor from the third dimension. Now there appears a new book, The Planiverse by Alexander Keewatin Dewdney, hailed by the publishers as a worthy successor to Flatland. For those of us who received our first challenge to think about lower and higher dimensions from Abbott's little volume, this claim must be viewed with scepticism. Yet the claim is correct.

Dewdney's volume is a fable for our own time that will delight anyone who likes a good story and who enjoys a mindstretching experience. Subtitled Computer Contact with a Two-Dimensional World, the book introduces us to "Yndrd" (Yendred), a creature we meet only on the video screen of a professor of computer science, Dewdney himself, and his team of students. The progressive encounters which intermesh the world of the observers and the world of the observed lead to an amazingly rich description of Arde, a twodimensional planet, complete with a welldeveloped technological society, worked out in fascinating detail. But this is no video game and still less a dry treatise on two-dimensional science. It is simultaneously a fine tale of adventure, as we accompany Yendred on his trek in search of higher meaning for existence, and the story of Dewdney and his students as they become caught up in the experience and are themselves educated through their contact with Arde.

The original reviewer of Flatland found some parts of the book tedious, as A Square went on at length about the physiology and psychology of perception, or described his society's blinkered view of women's education (an effective satirical device by Abbott, a distinguished schoolmaster well known for his liberal leadership in the cause of education for women). Similarly some readers of The Planiverse will find parts of it slow going, even though the author has relegated many technical asides to special boxes or to an appendix. Yet the pace of the book gives assurance that each new chapter will present something quite different, as the author strives to include material of interest to a wide range of readers - biology, astronomy,

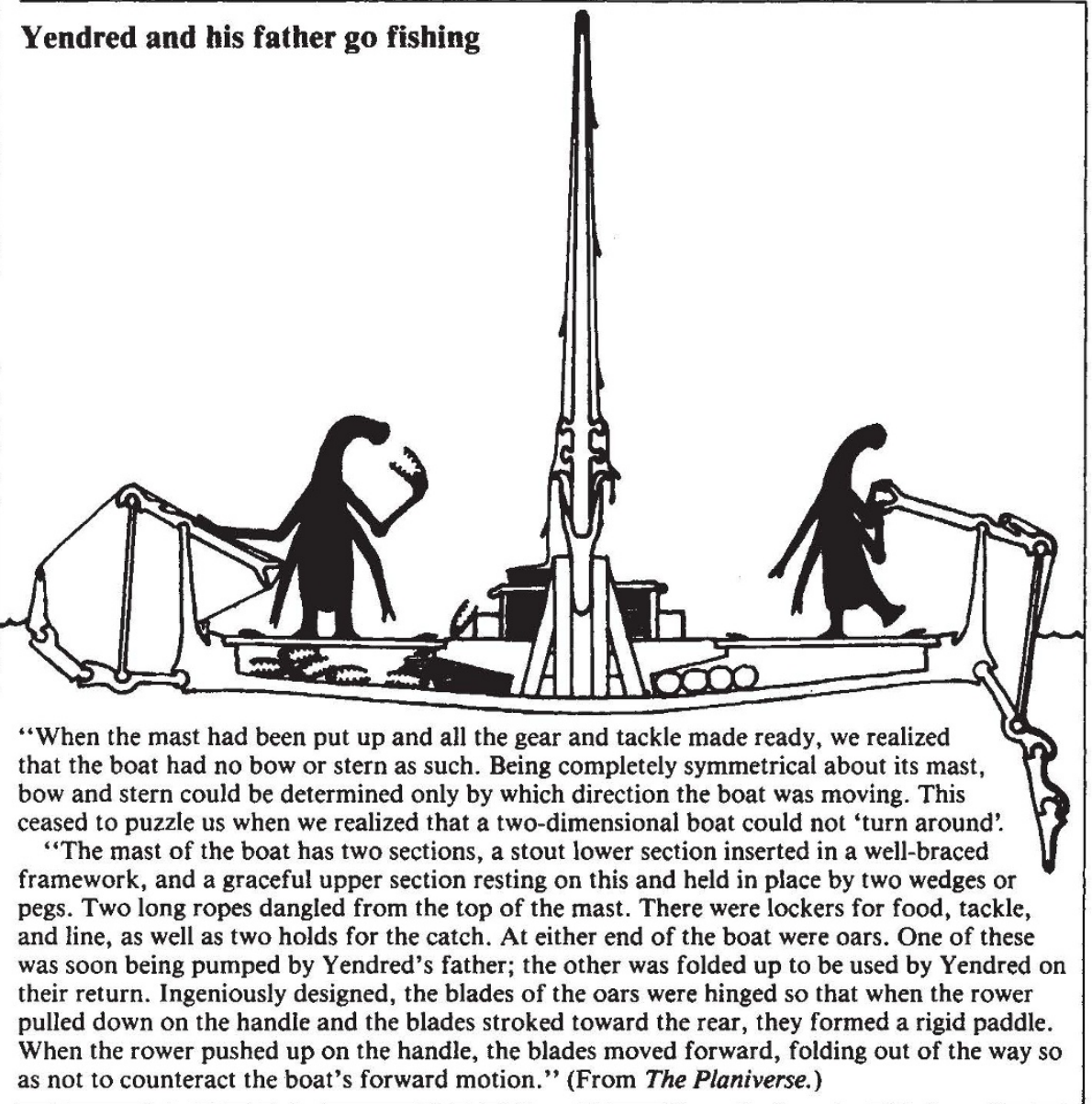

